ORIGINAL ARTICLE

\title{
Evaluation of production quality and mechanical behavior of low-cost shear connectors manufactured with perforated GFRP plates
}

\section{Avaliação da qualidade de produção e do comportamento mecânico de conectores de cisalhamento de baixo custo fabricados com placas perfuradas de PRFV}

\author{
John Kennedy Fonsêca Silva ${ }^{a}$ (i) \\ Renan Rocha Ribeiro ${ }^{\text {a }}$ \\ Rodrigo de Melo Lameiras ${ }^{\mathrm{a}}$ (D)
}

${ }^{a}$ Universidade de Brasília - UnB, Faculdade de Tecnologia, Brasília, DF, Brasil

Received 09 March 2020

Accepted 17 July 2020

\begin{abstract}
Insulated pre-cast concrete wall panels, also called sandwich panels, consist in two external concrete layers, in which an internal layer of thermal insulation material is inserted between, aiming better acoustic and thermal performance. One of the main concerns regarding the performance of these panels refers to the elimination of thermal bridges caused by metallic connectors, which jeopardize the panels' thermal efficiency. One of the proposals to solve this problem consists in the use of PERFOFRP connectors, which are plane plates with perforated holes through its thickness, which are embedded into the concrete plates, creating anchorage pins that enhance the shear strength and the layers' debonding resistance. This research had the objective of evaluating the production quality of this type of connector, produced with a low-cost and easy-to-use vacuum assisted resin infusion system; considering the effects of: (a) resin plate homogeneity, by taking samples from various locations on the plate; (b) fabrication repeatability; and (c) raw production materials' origin; on the results of: (I) ultimate tensile stress, (II) modulus of elasticity, and (III) volume fraction of fibre. Also, 18 specimens in the form of representative models of the shear connector in insulated pre-cast concrete wall panels, with six different hole configurations achieved by varying the holes' diameter and spacing, were subjected to push-out tests, to assess the holes' diameter and spacing effects on the mechanical performance of the connection in terms of ultimate load capacity and stiffness. The results indicated a production quality with a satisfactory level of characteristics variation, considering: the variability in different parts of a single composite plate, the variability between composite plates from different infusion process, and the variability between different production batches. Furthermore, the push-out tests demonstrated that the perforated connectors presented, when compared to non-perforated connectors: a gain in shear strength from $8 \%$ to $25 \%$, lower relative displacements, and higher levels of stiffness. It was also observed that connectors with $25.40 \mathrm{~mm}$ diameter holes presented better performance than connectors with $31.75 \mathrm{~mm}$ diameter holes; and that the reducing the hole spacing from 2.00 to 1.75 , for the $25.40 \mathrm{~mm}$ diameter specimens, caused a decrease in the load capacity of the connector. Thus, it was verified that variations on the hole's diameter and spacing influenced the load carrying capacity of the connection.
\end{abstract}

Keywords: composite structures, sandwich panels, shear connectors, PERFOFRP connectors, fibre reinforced polymers. 
desse tipo de conector, produzido com um sistema de infusão por resina à vácuo de baixo custo e de fácil uso; considerando os efeitos da: (a) homogeneidade da placa de PRFV; (b) repetibilidade de fabricação; e (c) origem das matérias-primas; sobre os resultados de: (I) tensão última à tração, (II) módulo de elasticidade, e (III) fração volumétrica de fibras. Além disso, 18 espécimes na forma de modelos representativos do conector de cisalhamento em painéis sanduíche, com seis configurações diferentes de perfuração obtidas por meio da variação do diâmetro e do espaçamento entre os furos, foram submetidos à ensaios push-out, para avaliar o efeito que essas variações produzem no desempenho mecânico da conexão em termos de capacidade de carga final e de rigidez. Os resultados indicaram uma qualidade de produção com um nível satisfatório de variação das características, considerando: a variabilidade em diferentes pontos de uma única placa, a variabilidade entre placas compostas por diferentes processos de infusão e a variabilidade entre diferentes lotes de produção. Além disso, os testes push-out demonstraram que os conectores perfurados apresentaram, quando comparados com conectores não perfurados: um ganho na resistência ao cisalhamento variando entre $8 \%$ e $25 \%$, deslocamentos relativos mais baixos e níveis mais elevados de rigidez. Observou-se também que os conectores com furos de $25.40 \mathrm{~mm}$ de diâmetro apresentaram melhor desempenho do que os conectores com furos de $31.75 \mathrm{~mm}$ de diâmetro; e que a redução do espaçamento entre furos de 2.00 para 1.75, para as amostras de $25.40 \mathrm{~mm}$ de diâmetro, causou uma diminuição na capacidade de carga do conector. Assim, verificou-se que as variações no diâmetro e no espaçamento do furo influenciaram a capacidade de carga da conexão.

Palavras-chave: estruturas compósitas, painéis sanduíche, conectores de cisalhamento, conectores PERFOFRP, polímeros reforçados com fibras.

How to cite: J. K. F. Silva, R. R. Ribeiro, and R. M. Lameiras, "Evaluation of production quality and mechanical behavior of low-cost shear connectors manufactured with perforated GFRP plates," Rev. IBRACON Estrut. Mater., vol. 14, no. 3, e14301, 2021, https://doi.org/10.1590/S1983-41952021000300001

\section{INTRODUCTION}

Insulated pre-cast concrete wall panels, also called sandwich panels, consist in two external concrete layers, in which an internal layer of thermal insulation material is inserted between, aiming better acoustic and thermal performance. To maintain the panel's integrity during the stages of lifting and transport, and throughout the building's lifespan, the use of connectors, which can either be shear-type or non-composites, is required. These connectors are anchored in both external concrete layers, passing through the inner layer of insulation material. The external layers are, usually, made of reinforced concrete and the inner layer of expanded polystyrene (EPS).

Sandwich panels can be classified as: (a) non-composites, in which the concrete layers behave mechanically independently, and, usually, one of them is a thick structural layer and the other is a thin non-structural layer; (b) composites, in which both concrete layers act as a single composite layer to sustain applied loads, such as bending; (c) partially composites, in which shear connectors connect the concrete layers but can only guarantee a moderate composite action [1]. The degree of composite action depends mainly on the stiffness, strength and connector's location along the panel [2].

Some advantages of the sandwich panels are: durability; economy; fire resistance; possibility of use in large spans; superior energetic performance and moisture protection when compared to other conventional building systems; resistance to impacts, thefts and vandalism; and easy surface finishing [1]. The sandwich panel is a significant development in the concept of sustainable architecture and a great advantage in the process of sustainable building certification. With new normative requirements for energetic performance, the industry has been adopting sandwich panels to improve building's thermal performance, while still taking advantage of the fast construction provided by concrete panels [3].

According to the PCI Committee Report [1], connectors for insulated pre-cast concrete panels have a variety of functions, among which it can be cited: sustaining the stress produced by the weight of the non-structural layer, supporting any horizontal load caused by winds or seismic actions; resisting the horizontal shearing due to panel bending. These connectors can be divided in two categories: (a) shear connectors, that are used mainly to transfer the in-plane shear forces between the two concrete layers; (b) non-composite connectors, that are designed only to hold the concrete layers connected.

Solid regions of concrete and steel trusses were the first type of connectors used in sandwich panels [4]-[6]. Even though panels with these types of connectors present a high degree of composite action when subjected to bending, a thermal bridge between the internal and external layer is created due to the high thermal conductivity of the steel and concrete, which, consequentially, compromises the thermal performance of the panel. According to MacCall [7], the use of steel-pin connectors, which also have such thermal issue, in an amount representing $0.08 \%$ of the sandwich panel area, may reduce the panel's thermal performance by up to $38 \%$. Being the thermal insulation one of the main requirements for this type of construction system, this is a relevant research topic. 
In order to solve this problem, fibre reinforced polymers (FRP) connectors have been developed, having the advantage of a reasonable mechanical strength and a considerably low thermal conductivity [8]. Nowadays, the most common FRP connectors are: glass-fibre reinforced polymer (GFRP) grids [9]; carbon-fibre reinforced polymer (CFRP) grids [10]-[12]; corrugated GFRP [13]; and shell GFRP [14]. Concerning the mechanical strength of FRP connectors, several tests have been conducted in order to assess the mechanical performance and composite action degree of this type of connector, such as: Naito et al. [3], that used double-shear tests to evaluate the performance of 14 types of commercial connectors, including FRP connectors, and developed a simplified tri-linear model of force versus relative displacement for use in structural performance analysis of sandwich panels; Hodicky et al. [15], that analysed the effect of connector spacing and insulation thickness in the strength of a CFRP grid connector, observing that an increase in insulation thickness leads to a decrease in the connector strength; and Tomlinson et al. [16], that tested connectors composed by angled bars of basalt-fibre reinforced polymer (BFRP) and analysed the effects of varying the bar diameter, inclination angle, and orientation of the diagonal connector relative to loading in tension and compression cases, in the bond between concrete and insulation layers and the overall performance of the connector.

In this sense, the PERFOFRP connectors were developed aiming both better mechanical and thermal insulation performance. This type of connector for sandwich panels was originally proposed by Lameiras et al. [17], [18].

The PERFOFRP connectors are made of GFRP, which provides an excellent thermal insulation performance due to its low thermal conductivity $(0.04 \mathrm{~W} / \mathrm{mK})$ when compared to steel $(50.2 \mathrm{~W} / \mathrm{mK})$ and concrete $(0.8 \mathrm{~W} / \mathrm{mK})[19]$. The connector is fabricated as a plane plate with perforated holes through the thickness, which are embedded into the concrete plates, creating anchorage pins that enhance the shear strength and the layers' debonding resistance. The PERFOFRP connectors can also be easily standardized for mass production or customized for a specific application and require neither large nor expensive industrial facilities for fabrication.

The PERFOFRP was further studied by Lameiras et al. [20], [21], in studies performed at University of Minho, in which push-out tests were conducted aiming the assessment of the connector's resistance capacity. Chen et al. [22] and Norris and Chen [23], at Iowa State University, analysed the flexural behaviour of similar connectors. Recently, Huang and Dai [2] conducted, at Hong Kong Polytechnic University, a series of direct shear tests of this type of connector, assessing the effect of the connector's thickness and height in its shear resistance.

The aforementioned researches attested the viability of the PERFORFRP and demonstrated a satisfactory degree of composite action, in terms of strength and stiffness, in sandwich panels produced with this connector. However, they indicate that there is limited information regarding this type of connector since the relation between the connector's geometric parameters and performance is still unknown. Thus, the next logical step is the study of the properties and factors that affect the connector's performance, aiming the development of design guidance.

This research has two main objectives: (a) assess the production quality of a low-cost fabrication system of shear connectors for sandwich panels, produced from plane perforated plates of GFRP according to the PERFOFRP proposal; (b) asses the mechanical behaviour of the produced connectors, by means of double-shear push-out tests on representative models of the shear connector in insulated pre-cast concrete wall panels, with hole of various diameter and spacing.

\section{MATERIALS AND EXPERIMENTAL PROGRAM}

The experimental program was divided in two main stages: (a) production and evaluation of production quality of the GFRP composites plates used in the shear connectors fabrication, by means of ultimate tensile stress, modulus of elasticity and volume fraction of fibre test results; (b) fabrication and testing of the shear connectors, by means of double-shear push-out tests of representative models of the shear connector in insulated pre-cast concrete wall panels, with six different hole configurations achieved by varying the holes' diameter and spacing.

\subsection{Production and evaluation of production quality of GFRP composite plates}

GFRP composite plates were produced aiming the fabrication of shear connectors for insulated pre-cast concrete wall panels, according to connectors previously studied by Lameiras et al. [17], [18], [20], [21] and Huang and Dai [2]. A total of 27 GFRP composite plates of $25 \mathrm{~cm}$ width, $70 \mathrm{~cm}$ length and approximately $2.30 \mathrm{~mm}$ thickness was produced during the experimental program, used for both production quality evaluation and mechanical tests in the representative models. The plate production was divided in three batches, denominated Group 01, 02 and 03, each composed by, respectively, 6, 10 and 11 plates. Each group/batch was produced with resin, catalyst, and fibres from the same origin/manufacturer's batch. All composites were composed by five layers of fibre glass of $450 \mathrm{~g} / \mathrm{m}^{2}$, embedded in polyester resin. 
A vacuum assisted resin infusion process, performed with an in-house developed system, was used to produce the composites. This in-house developed system is one of the original contributions of this work, since it used low-cost and easy-to-use materials, that can be acquired and used at, virtually, any place and ambient. Figure 1 presents the main stages of the composites fabrication process, which will be further detailed in the topics 2.1.1, 2.1.2, 2.1.3, e 2.1.4. The production size of the composite plates was defined by the available vacuum level, and the viscosity and working time of the resin.

Aiming the evaluation of the production quality of the produced composite plates, samples were extracted from random regions of the plate to allow tests for ultimate tensile strength and volume fraction of fibre determination.

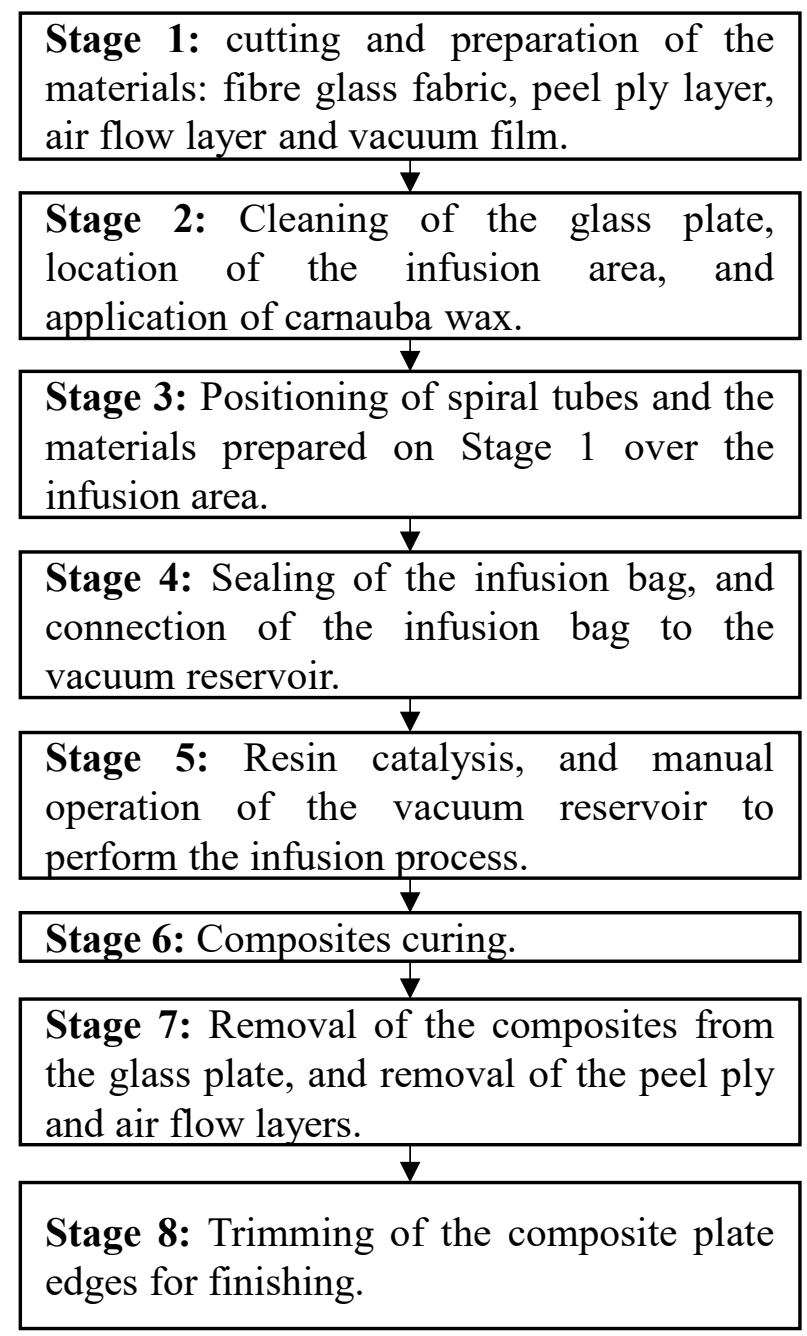

Figure 1. Stages of the composites fabrication process.

\subsubsection{In-house developed system for vacuum assisted resin infusion}

The vacuum assisted resin infusion system, that was developed in-house for this work, is composed by four main components, with the following functions:

a) Resin reservoir: a reservoir produced from polyvinyl chloride (PVC) in which the catalysed resin is deposited and is left ready to be suctioned during the infusion process;

b) Infusion bag: an air-tight bag into which the resin flows, being composed by the following sequential layers, from top to bottom: one glass plate; one peel ply; five fibre glass fabrics; one peel ply; one air flow layer; one vacuum film. The purpose of each layer is described in 2.1.2. The vacuum film, which is the last layer in the system, is sealed in its external perimeter with a silicon bead that guarantees its adhesion to the glass plate. Inside the infusion 
bag, just before positioning the vacuum film, two $70 \mathrm{~cm}$ spiral tube lines were placed in opposite longitudinal sides, and denominated vacuum and infusion lines. The vacuum line is used to apply vacuum in the system, being positioned $5 \mathrm{~cm}$ from the border of the glass fibre fabrics. The infusion line is used to infuse the resin in the system, being positioned close to the glass fibre fabrics. In both lines, a T-shaped connection is fixed in the central region, which allows access to the infusion bag by the other parts of the system;

c) Vacuum reservoir: a system of interconnected hydraulic components with $100 \mathrm{~mm}$ diameter, composed by pipes, cap, and T- and L-shaped connections. The vacuum reservoir works with an inner pressure isolated from the atmosphere, which promotes the stabilization and vacuum reserve of the system. It has four ends composed by caps, to which three gate valves of 0.5 in (denominated vacuum, infusion and scape) and an analogic vacuum gauge (with 0.0 to $-1.0 \mathrm{~atm}$ measuring range) are connected, in order to allow measurement of the negative pressure inside the infusion system. Furthermore, the vacuum reservoir guarantees the safety functioning for the vacuum pump, acting as a drain to prevent that excess of resin reach the pump;

d) Vacuum pump: a device responsible for the application of vacuum inside the system. In the present work, an air compressor, working in inverse mode, was used (i.e., the air suction socket) usually used as supply for the compressor pressure vessel, was employed as the suction socket in the infusion system, allowing the application of vacuum.

All four main components of the vacuum assisted resin infusion system were interconnected by reinforced transparent plastic hoses, of 0.5 in diameter, in the following order: resin reservoir, infusion bag, vacuum reservoir, and vacuum pump. A valve for opening and closing the resin flow into the system, denominated as resin valve, was placed in the hose connecting the resin reservoir to the infusion bag.

\subsubsection{Assembly of the vacuum assisted resin infusion system}

The composite plates production was initiated by the assembly of the production system. The assembly process initiated with the cut of the glass fibre fabric, peel ply and air flow layers, in $25 \mathrm{~cm}$ by $70 \mathrm{~cm}$, and vacuum film in $90 \mathrm{~cm}$ by $120 \mathrm{~cm}$, rectangles (Figure 2a). Next, the glass plate was cleaned to eliminate any contamination source in the composite production (Figure $2 \mathrm{~b}$ ).

Then, the vacuum bag assembly was initiated, by locating the infusion area with use of white adhesive tapes over the glass plate (Figure 2c). In this area, three layers of carnauba wax with demoulding agent were applied in intervals of $30 \mathrm{~min}$. After the drying of the last wax layer, the infusion bag layers and the spiral tubes were positioned over the glass plate, according to the order described in 2.1.1, over the already located and waxed infusion area (Figure 2d).

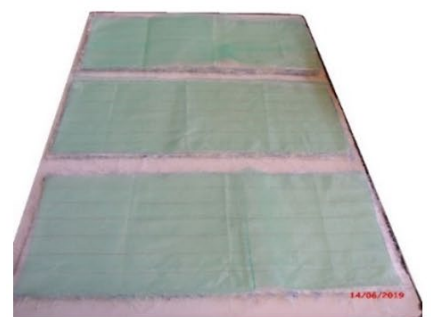

(a)

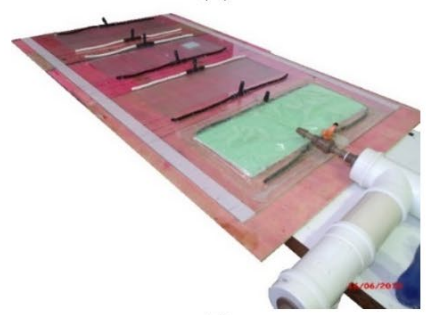

(d)

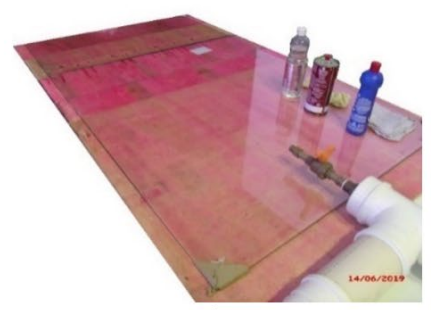

(b)

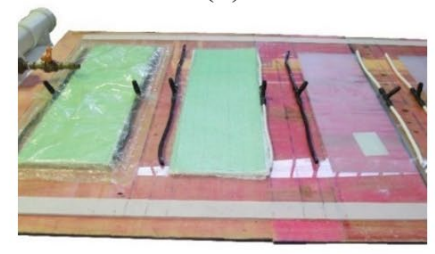

(e)

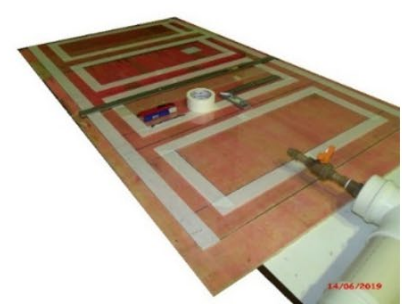

(c)

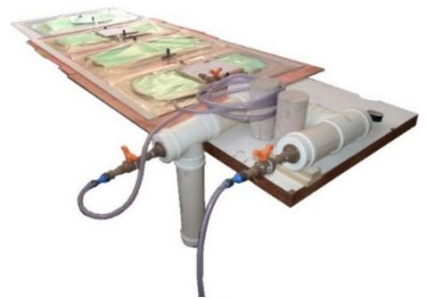

(f)

Figure 2. GFRP composite fabrication process: (a) curing and preparation of the materials; (b) cleaning of the glass plate; (c) location of the infusion area and application of carnauba wax; (d) positioning of the pipes, spiral tubes and materials over the glass plate; (e) lateral view of the positioning of the pipes, spiral tubes and materials over the glass plate; (f) resin infusion system ready for use, requiring only the positioning of the last pipes. 
The peel ply layer has the purpose of guaranteeing the demoulding, since it does not present post-infusion adhesiveness to the glass plate and to the GFRP composite, being easily removed after the partial cure of the composite $(12 \mathrm{~h})$. The air flow layer, by its turn, has the purpose of guaranteeing a certain free space between the peel ply and the vacuum film layer, to allow the passage of resin and guarantee an air exit.

With the infusion bag assembled, the reinforced plastic hoses, connecting the resin reservoir and the vacuum pump to the T-shaped connections of the spiral tubes inside the infusion bag, were connected. This concluded the assembly of the vacuum assisted resin infusion system (Figure 2e and Figure 2f).

\subsubsection{Production of GFRP composite plates}

For each produced plate of $25 \mathrm{~cm}$ by $70 \mathrm{~cm}$, it was used approximately $550 \mathrm{~g}$ of polyester unsaturated resin, obtained by the condensation of carboxylic diacids and glycols, in a solution of styrene monomer $\left(\mathrm{C}_{8} \mathrm{H}_{8}\right)$, catalysed with $1.0 \%$, in mass, of methyl ethyl ketone peroxide $\left(\mathrm{C}_{4} \mathrm{H}_{10} \mathrm{O}_{4}\right)$, according to the information provided by the resin manufacturer.

Previously to the resin application, the infusion bag and the vacuum reservoir were tested to verify whether leakage points existed. Following, the inner negative pressure was elevated to a $0.80 \mathrm{~atm}$ value and stabilized at this level. The infusion initiated with the addition of the catalyst to the resin, in quantities and proportions already mentioned. Then, by manual setting of the valves, the catalysed resin was suctioned from the resin reservoir to the infusion bag and, slowly, all the layers inside the infusion bag were impregnated with resin. This stage was performed in approximately $10 \mathrm{~min}$, with minor variation depending on the temperature and the viscosity of the resin in the moment of infusion of each GFRP composite plate.

Once the suction stage was finished, the resin valve was closed. After $15 \mathrm{~min}$ of the beginning of the catalysis, the resin started to present a gel-like aspect, with high viscosity and a low workability that hindered any suction process impossible. After this period, the vacuum pump was kept on for more $30 \mathrm{~min}$, aiming the removal of any air excess impregnated in the composite. In the end of this $30 \mathrm{~min}$ period, the resin passed to a rigid state and, since this made impossible any air entrance into the composite plate, the vacuum pump was turned off (Figure 3a).

After $12 \mathrm{~h}$ of the start of the resin catalyzation, the GFRP composite plates were under partial cure state and could be removed from the glass plate, allowing the production of the next plate. After $24 \mathrm{~h}$ of the start of the resin catalyzation, the composite plates reached a complete cure state, with virtually full resin stiffness, and could have its borders trimmed with the aid of a circular table saw. Lastly, the peel ply and air flow layers were removed, and the plates were ready for use (Figure 3b).

At this point, the composite is at full cure and can be mechanically loaded. All the produced plates followed the proceedings described, with small and specific adjustments in the disposition, and geometry, of the pipelines and other components of the infusion system.

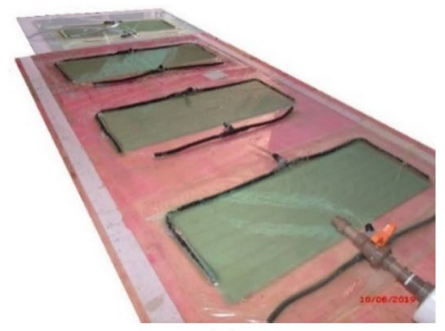

(a)

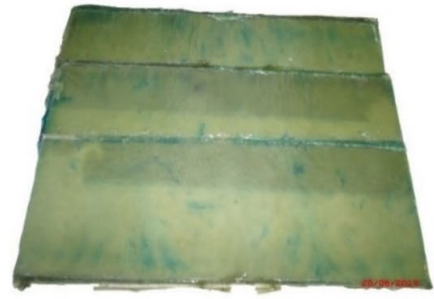

(b)

Figure 3. GFRP composite plates production process: (a) aspect of the plates immediately after partial curing, still inside the infusion bag; (b) aspect of the composite plates after the removal of vacuum, and the air flow and peel ply layers.

\subsubsection{Evaluation of the production quality of the GFRP composites plates}

The evaluation of the production quality of the GFRP composite plates encompassed three characterization procedures: (a) a dimensional homogeneity analysis, by measurement of the plate thickness $(\varepsilon)$, which refers to geometric conformity; (b) the mechanical characterization of the main properties of interest (i.e., ultimate tensile stress $\left(\sigma_{p t . u}\right)$, longitudinal $\left(E_{p t . l}\right)$ and transversal tensile modulus of elasticity $\left(E_{p t . t}\right)$, and Poisson's ratio $\left.(v)\right)$, which refer to composite strength conformity; (c) the determination of the volume fraction of fibre $\left(V_{f}\right)$, which refer to 
the material composition conformity. The characterization procedures provided not only parameters for the evaluation of the production quality, but also for the overall characterization of the composites produced and used in this work. All characterization procedures were performed in at least two samples per plate taken from random regions.

The evaluation of production quality of the GFRP composite plates was performed by using three parameters: ultimate tensile stress, volume fraction of fibres, and modulus of elasticity, as shown on Figure 4. These three parameters were assessed in three different levels:

a) Along the extension of each plate, aiming the assessment of variations that may have occurred in the infusion processes;

b) Among different plates belonging to the same group/batch, aiming the assessment of variations that may have occurred between different infusion processes;

c) Among different groups/batches, aiming the assessment of the reproducibility of the composites characteristics when produced with materials from different sources/manufacturer's batch.

Up to three statistical tests were applied to the data, as shown on Figure 4: analysis of the magnitude of the coefficient of variation; variance analysis; and a normality test. The choice of which tests were to be applied to each dataset depended on the minimum amount of data required by a given test and the amount of available data on the dataset.

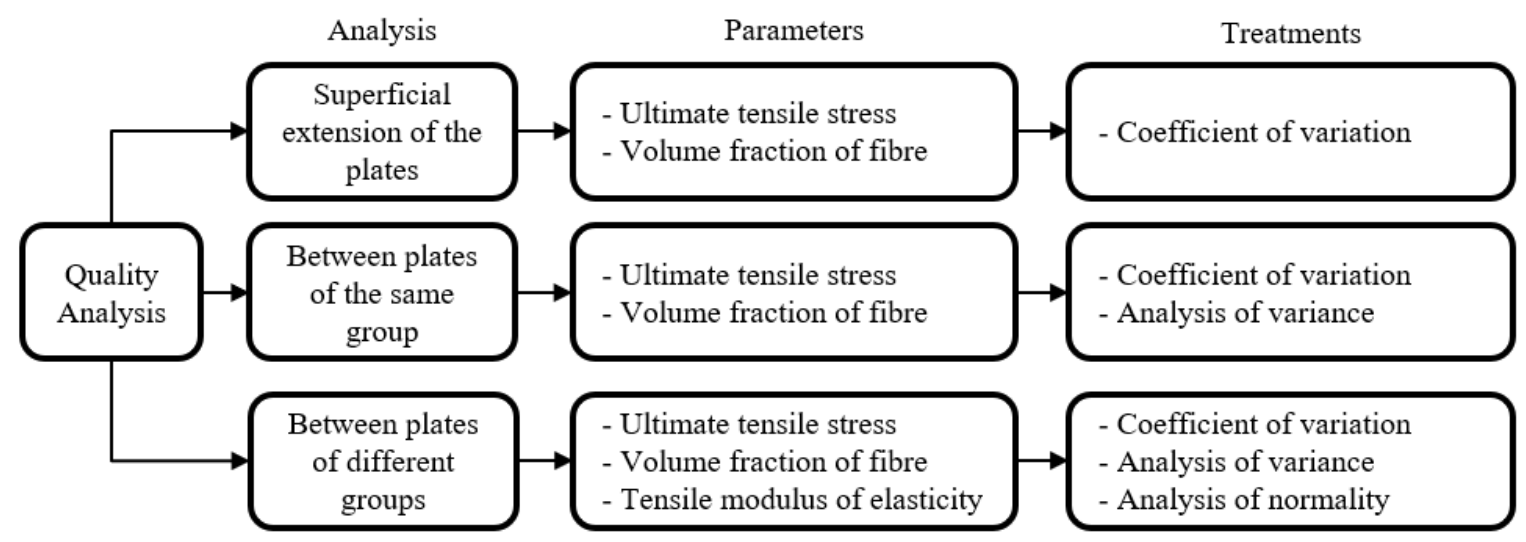

Figure 4. Evaluated parameters, with the respective statistical treatments, in each of the three analyzes level considered.

Samples in the form of $25 \mathrm{~cm}$ by $2.50 \mathrm{~cm}$ rectangles, with approximately $2.30 \mathrm{~mm}$ thickness, were used to perform the ultimate tensile stress and modulus of elasticity tests (Figure 5). The tests were performed in a universal testing machine with load capacity of $300 \mathrm{kN}$ and displacement control. The ultimate tensile stress was determined in a total of 59 specimens, which were also used in the thickness measurement. The tests were conducted according to ASTM D3039 [24], which specifies parameters such as sample geometry and testing machine's displacement velocity. The specimens were clamped, at the inferior and superior extremities, by a compressed air pressure system, and tensioned from the inferior extremity with a constant velocity of $2 \mathrm{~mm} / \mathrm{min}$. At the extremity of each specimen, two GFRP plates of $25 \mathrm{~mm}$ by $25 \mathrm{~mm}$ were fixed, aiming a better distribution of the stress applied by the clamping claws of the testing machine (Figure 6). The load readings were performed with the software and the data-acquisition system of the testing machine. The strain measurement, required for the modulus of elasticity determination, was performed in 14 specimens, of which at 12 the longitudinal strains were measured and at 2 the transversal strains were measured, to provide longitudinal and transversal modulus of elasticity estimates, respectively. The strain gauges were positioned in the central portion of the specimens, and connected to a data-acquisition system. 


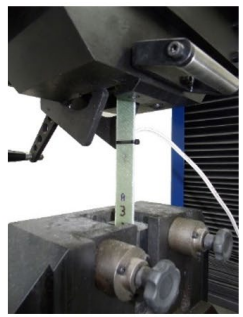

(a)

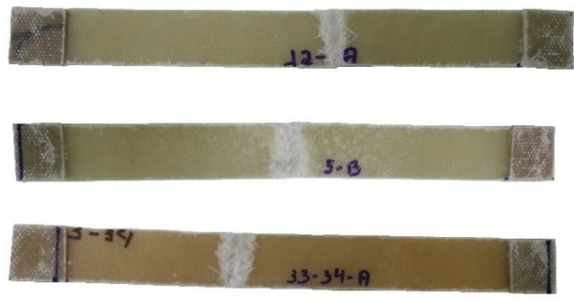

(b)

Figure 5. Ultimate tensile stress test: (a) test execution; (b) specimens after failure.

Samples in the form of $25 \mathrm{~mm}$ by $25 \mathrm{~mm}$ specimen were used for the volume fraction of fibre determination $\left(V_{f}\right)$, in a total of 53 specimens. The procedure consisted in submitting these specimens to a $565^{\circ} \mathrm{C}$ temperature, during $6 \mathrm{~h}$, according to ASTM D2584 [25]. The mass of the specimens was measured before and after this heating process. The mass loss, caused by the volatilization of the resin, allows the computation of the volume fraction of fibre.

\subsection{Push-out tests}

\subsubsection{Fabrication of connectors and push-out test specimens}

Representative models of the shear connector in insulated pre-cast concrete wall panels, to allow double-shear pushout tests, in the form of concrete prims, were moulded following the geometries suggested by Huang and Dai [2], but with connectors' holes close to that presented by Lameiras et al. [17], [18], [20], [21]. However, the size of the connectors differed from both works. The connector's geometry was defined aiming the maximum possible size considering the model geometry used in the push-out test, but allowing a minimum concrete confinement of $50 \mathrm{~mm}$ in the connector's superior and inferior parts, besides a minimum cover of $25 \mathrm{~mm}$. The Figure 7 presents the test specimen.

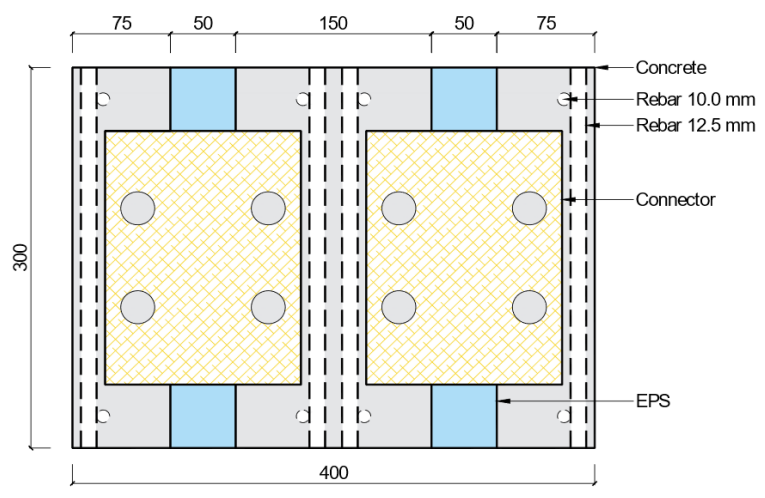

(a)

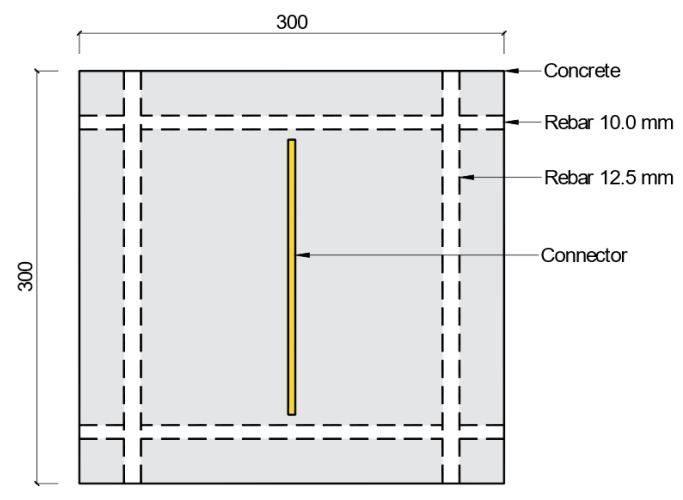

(b)

Figure 6. Test specimen: (a) front view; (b) side view.

For the fabrication of the connectors, the GFRP composite plates were saw into dimensions of $15 \mathrm{~cm}$ by $20 \mathrm{~cm}$, which was the final size of the connectors tested in this work. These plates were randomly obtained from the Groups 01,02 and 03 , and sorted before the perforation, aiming a better homogeneity of the tested connectors' mechanical characteristics. The sawing was performed in a circular table saw. Next, the perforation of the connectors was performed with a set of hole saws and a bench drill press. The adopted holes had diameters of $25.40 \mathrm{~mm}$ and $31.75 \mathrm{~mm}$, and were spaced by $1.75,2.00$ and 3.00 times the hole's diameters, with such spacing taken from the centre of the holes. The PERFOFRP connectors were centralized in the specimen, passing through the insulating material, before the concrete moulding. After the moulding, the connector was embedded in both concrete layers adjacent to the insulating material, i.e. two PERFOFRP connectors were symmetrically positioned in each push-out test specimen. To assess the efficiency 
of the perforated connectors, control specimens were produced containing a non-perforated GFRP connector. Three replicate specimens of each connector type were tested. In these tests, the analysed parameters were the hole's diameter and spacing, aiming the assessment of the effect of such variables in the ultimate load capacity and connection stiffness

The identification of test specimens followed the nomenclature format "SP-X-Y-R (n)", in which: SP abbreviates the term specimen; $\mathrm{X}$ encodes the connector's hole diameter, in millimetres; $\mathrm{Y}$ encodes the hole spacing, in number hole's diameters; $r$ indicates the replicate, either A, B or C; and $\mathrm{n}$ encodes a unique identifier associated to the specimen type, from 1 to 6 , for concise reference. For the control specimen, that contained a connector without holes, the "X-Y$\mathrm{r}$ " identifiers were substituted by "CTL", abbreviating the term control. Table 1 presents the connector's main characteristics of each specimen tested. The Figure 7 illustrates the hole configuration of the connectors tested.

Table 1. Specimens' identification and their main connector's characteristics.

\begin{tabular}{cccc}
\hline \multirow{2}{*}{ Specimen } & $\begin{array}{c}\text { Amount of tested } \\
\text { specimen }\end{array}$ & Diameter & \multicolumn{2}{c}{ Spacing } \\
\cline { 3 - 5 } & 3 & {$[\mathbf{m m}]$} & 25.40 \\
\hline SP-25.40-1.75 & 3 & 25.40 & 1.75 \\
\hline SP-25.40-2.00 & 3 & 25.40 & 2.00 \\
\hline SP-25.40-3.00 & 3 & 31.75 & 3.00 \\
\hline SP-31.75-2.00 & 3 & 31.75 & 2.00 \\
\hline SP-31.75-3.00 & 3 & - & 3.00 \\
\hline SP-CTL & & & - \\
\hline
\end{tabular}

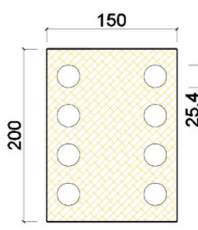

(a)

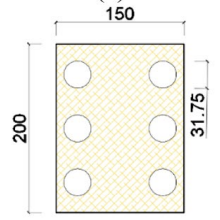

(d)

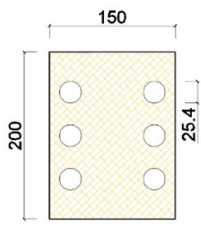

(b)

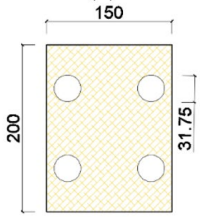

(e)

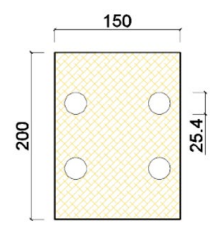

(c)

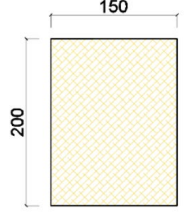

(f)

Figure 7. Hole configuration of the connectors tested: (a) SP-25.40-1.75; (b) SP-25.40-2.00; (c) SP-25.40-3.00; (d) SP-31.75-2.00; (e) SP-31.75-3.00; (f) SP-CTL.

The holes were aligned to be centralized to the region that would be embedded in concrete. The number of holes was calculated based on the hole diameter and spacing, considering that the most external holes had to be in a distance of, at least, half of the hole spacing. After computing the number of holes, the set was centralized to the connector's geometric centroid. A perforation template was employed to aid in the dimensional precision of the drilling.

The preparing for the moulding of specimens for the push-out test involved the following stages: formwork fabrication; rebar placement, with $12.5 \mathrm{~mm}$ diameter bars for the longitudinal steel, and $10.0 \mathrm{~mm}$ bars for the transversal steel; cut of EPS plates to emulate the insulation layer; fixation of the connectors through the insulation layer; and final assembly of the prism. Lastly, the moulding of the prisms was performed with a ready-mix concrete, with consistency of $10 \pm 2 \mathrm{~cm}$ in the slump test. The concrete's mechanical parameters values were compressive strength of $37.5 \mathrm{MPa}$, tensile strength of $4.5 \mathrm{MPa}$, and modulus of elasticity of $31.0 \mathrm{GPa}$, evaluated at 28 days in cylindric specimens of $10 \mathrm{~cm}$ by $20 \mathrm{~cm}$ size, cured under the same ambient of the prisms. 


\subsubsection{Push-out test execution}

The push-out tests were performed according to the test setup shown in the Figure 8. The test consists in inserting, inside the reaction frame, these parts in the following order: prism supports; steel plate supports; a ball-and-socket joint for load direction adjustment; the load cell, with a load capacity of $500 \mathrm{kN}$ produced by HBM Test and Measurement; and the hydraulic actuator, with load capacity of $500 \mathrm{kN}$ produced by Enerpac. The execution of the push-out test consisted in, basically, supporting the external concrete layers and applying a loading to the central concrete layer. This induced a shearing force in the GFRP connectors inside the EPS insulation layer.

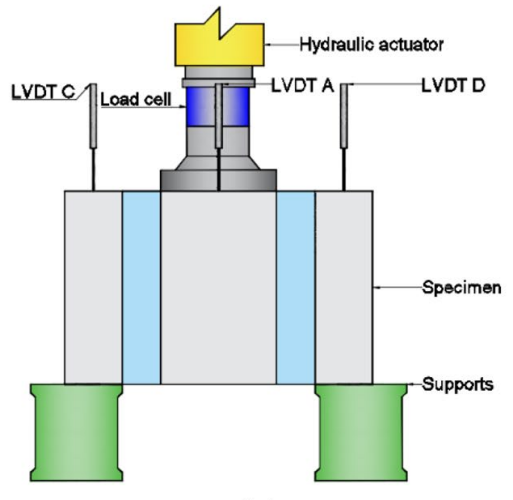

(a)

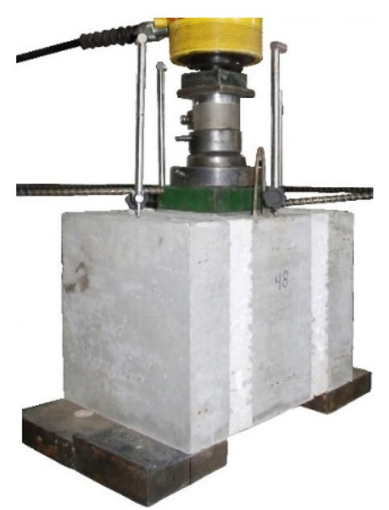

(b)

Figure 8: Push-out test: (a) schematic illustration; (b) test execution.

The displacements were measured with a deflectometer of the linear variable differential transducer (LVDT) type, with a total path of $50 \mathrm{~mm}$ produced by HBM Test and Measurement. A single LVDT was positioned in each external concrete layer, denominated $\mathrm{C}$ and $\mathrm{D}$, and two LVDTs were positioned in the internal concrete layer, denominated A and $\mathrm{B}$. The relative displacement was calculated computing the difference between the average of the LVDTs A and B, which represent the total displacement of the connectors, and the average of the LVDTs C and D, which represent the settlement at the supports and imply a rigid body motion of the entire prism. This procedure allowed the determination of the relative displacement of the connectors.

Rubber plates were placed in the contact areas between the supports and the external concrete layers, and between the ball-and-socket joint and the internal concrete layer, aiming to allow better accommodation of surface imperfections. The data was sampled at a frequency of $1.0 \mathrm{~Hz}$, with a Spider 8 data-acquisition system, controlled by the software Catman 4.5.

The testing procedure consisted in manually controlling a hydraulic pump, produced by Enerpac, that, by its turn, controlled the loading applied by the hydraulic actuator. The loading rate was approximately constant at a value of $8.1 \mathrm{kN} / \mathrm{min}$. The loading was applied until the detection of the connector's failure, which was verified by a sudden drop in the load cell readings. From this point onwards, the loading rate was kept constant until approximately $50 \%$ of the ultimate load. After testing, the connectors were removed from inside the prims, for failure mode analysis.

\section{RESULTS AND DISCUSSIONS}

\subsection{Production cost analysis of the in-house developed infusion system}

A cost analysis of the production was performed aiming to compare the cost of the produced composites to the prices of composites commercially found on Brazil. Considering only the costs of raw materials (i.e. not including machinery and labour costs) the composites produced in this work costed $107.34 \$ / \mathrm{m}^{2}$, or $546.38 \mathrm{R} \$ / \mathrm{m}^{2}$ with the current exchange rate. Currently, composites could be found on the market with prices of the order of $1,091.46 \$ / \mathrm{m}^{2}$, or $5,555.56 \mathrm{R} \$ / \mathrm{m}^{2}$ with the current exchange rate, which is $1,016.79 \%$ higher than the production costs with the method described in this work. 


\subsection{Composite characterization}

The Table 2 shows the results obtained in the measurement of thickness $(\varepsilon)$, ultimate tensile stress $\left(\sigma_{p t . u}\right)$, and volume fraction of fibre $\left(V_{f}\right)$, and the respective coefficients of variation $(\mathrm{CoV})$ and number of samples tested.

Table 2. Thickness, ultimate tensile stress and volume fraction of fibre of the GFRP plates

\begin{tabular}{|c|c|c|c|c|c|c|c|c|c|}
\hline \multirow{3}{*}{ GFRP plate } & \multicolumn{3}{|c|}{ Thickness } & \multicolumn{3}{|c|}{ Ultimate tensile stress } & \multicolumn{3}{|c|}{ Volume fraction of fibre } \\
\hline & Sample & Avg. & $\mathrm{CoV}$ & Sample & Avg. & $\mathrm{CoV}$ & Sample & Avg. & $\mathrm{CoV}$ \\
\hline & size & [mm] & {$[\%]$} & size & [MPa] & {$[\%]$} & size & {$[\%]$} & {$[\%]$} \\
\hline 01 & 2 & 2.20 & 3.33 & 2 & 180.77 & 9.10 & 2 & 45.92 & 1.05 \\
\hline 02 & 2 & 2.29 & 1.68 & 2 & 196.14 & 4.85 & 2 & 38.45 & 0.60 \\
\hline 03 & 2 & 2.30 & 1.81 & 2 & 212.56 & 2.17 & 2 & 43.24 & 1.88 \\
\hline 04 & 2 & 2.53 & 0.40 & 2 & 181.17 & 17.47 & 2 & 37.21 & 1.51 \\
\hline 05 & 2 & 2.25 & 0.81 & 2 & 154.33 & 6.69 & 2 & 38.06 & 3.67 \\
\hline 06 & 2 & 2.60 & 1.93 & 2 & 126.66 & 9.81 & 1 & 37.80 & - \\
\hline 11 & 2 & 2.54 & 12.60 & 2 & 161.41 & 2.69 & 2 & 35.79 & 3.38 \\
\hline 12 & 2 & 2.53 & 4.42 & 2 & 178.50 & 1.66 & 2 & 33.81 & 2.29 \\
\hline 13 & 2 & 2.27 & 0.22 & 2 & 162.93 & 2.80 & 2 & 38.59 & 1.48 \\
\hline 14 & 2 & 2.41 & 11.14 & 2 & 155.24 & 12.35 & 1 & 36.15 & - \\
\hline 15 & 2 & 2.55 & 1.24 & 2 & 168.98 & 0.46 & 2 & 36.86 & 0.02 \\
\hline 16 & 3 & 2.11 & 7.01 & 3 & 172.79 & 15.13 & 3 & 44.06 & 2.49 \\
\hline 17 & 3 & 2.58 & 5.60 & 3 & 139.66 & 10.61 & 3 & 39.19 & 1.97 \\
\hline 18 & 2 & 2.11 & 8.00 & 2 & 165.05 & 7.32 & 2 & 41.16 & 3.04 \\
\hline 19 & 3 & 2.25 & 1.98 & 3 & 165.15 & 10.64 & 2 & 35.86 & 0.05 \\
\hline 20 & 2 & 1.97 & 2.03 & 2 & 184.62 & 5.31 & 2 & 40.84 & 1.20 \\
\hline 31 & 2 & 2.27 & 4.77 & 2 & 162.25 & 1.27 & 1 & 36.48 & - \\
\hline 32 & 2 & 2.42 & 1.52 & 2 & 134.50 & 5.15 & 1 & 37.03 & - \\
\hline 33 & 3 & 2.39 & 4.04 & 3 & 156.46 & 17.45 & 3 & 39.34 & 0.10 \\
\hline 34 & 2 & 2.36 & 0.28 & 2 & 160.96 & 10.49 & 2 & 39.13 & 2.08 \\
\hline 35 & 2 & 2.27 & 1.10 & 2 & 124.76 & 19.82 & 2 & 39.38 & 0.09 \\
\hline 36 & 2 & 2.19 & 1.82 & 2 & 172.55 & 7.30 & 2 & 40.38 & 2.95 \\
\hline 37 & 2 & 2.32 & 0.36 & 2 & 147.54 & 11.26 & 2 & 37.65 & 1.85 \\
\hline 38 & 3 & 2.28 & 0.66 & 3 & 175.26 & 1.09 & 2 & 40.26 & 0.00 \\
\hline 39 & 2 & 2.24 & 9.29 & 2 & 170.09 & 8.59 & 2 & 38.38 & 3.54 \\
\hline 40 & 2 & 2.16 & 0.54 & 2 & 160.31 & 9.52 & 2 & 41.74 & 1.02 \\
\hline 41 & 2 & 2.20 & 5.84 & 2 & 163.82 & 1.81 & 2 & 41.24 & 2.49 \\
\hline Avg. & & 2.32 & 3.50 & & 164.24 & 7.88 & & 39.04 & 1.69 \\
\hline
\end{tabular}

The Figures 9a, 9b, and 9c present the stress-strain curves obtained in the longitudinal modulus of elasticity determination tests under tensile stress of the composites. The curves presented comprise approximately half of the test, up to the moment in which the maximum displacement of the strain gauges used was reached. In other words, the complete stress-strain curves could not be obtained in these tests due to a technical limitation of the type of strain gauges used, since their maximum measurable strain is lower than the maximum strain the composites can sustain. It could be observed, by visual inspection, that the composites presented a remarkably fragile behaviour during the tensile stress tests. The same fragile behaviour was observed during the push-out tests with the PERFOFRP connectors.

The Figure 9d presents the stress-strain curve obtained in the transversal modulus of elasticity determination tests under tensile stress, in which the curve encompasses the entire test due to the lower magnitude of strains produced. For both modulus of elasticity tests, strong linear correlations were observed, with a $\mathrm{R}^{2}$ coefficient of 0.997 and 0.992 for the longitudinal and transversal modulus, respectively. 


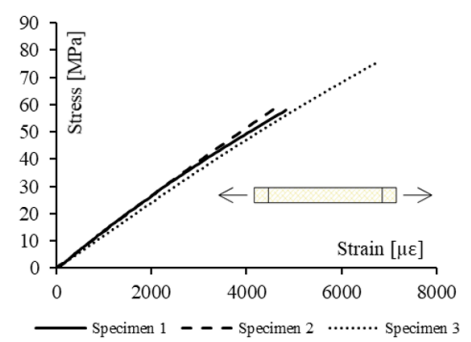

(a)

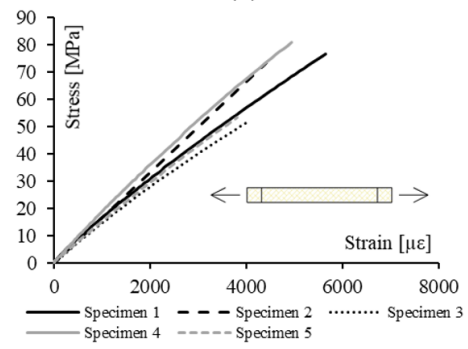

(c)

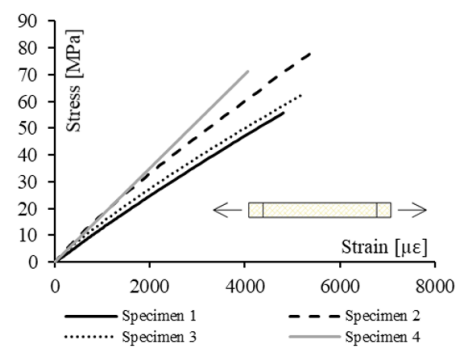

(b)

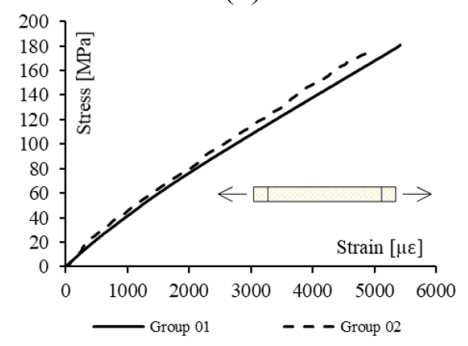

(d)

Figure 9. Experimental stress-strain curves: (a) longitudinal tensile modulus of elasticity for Group 01; (b) longitudinal tensile modulus of elasticity for Group 02 ; (c) longitudinal tensile modulus of elasticity for Group 03; (d) transversal tensile modulus of elasticity for Groups 01 and 02.

From the data presented in the Figures 9a, 9b, and 9c, a linear model was adjusted to obtain the value of the longitudinal modulus of elasticity for the composite. An average value of $13.35 \mathrm{GPa}$ was obtained, as shown on Table 3 .

Table 3. Longitudinal tensile modulus of elasticity for GFRP plates

\begin{tabular}{|c|c|c|c|}
\hline \multirow{3}{*}{ Group } & \multicolumn{3}{|c|}{ Longitudinal tensile modulus of elasticity } \\
\hline & Sample & Avg. & CoV. \\
\hline & size & [GPa] & [\%] \\
\hline 01 & 3 & 12.46 & 4.39 \\
\hline 02 & 4 & 13.28 & 8.82 \\
\hline 03 & 5 & 14.30 & 11.31 \\
\hline Avg. & & 13.35 & 8.17 \\
\hline
\end{tabular}

From the data presented in the Figure 9d, a linear model was adjusted to obtain the value of the transversal modulus of elasticity for the composite, being found an average value of $36.36 \mathrm{GPa}$. Then, by taking the quotient between the longitudinal and transversal modulus of elasticity, the average Poisson's ratio value was computed as 0.35 , as shown on Table 4.

Table 4. Transversal modulus of elasticity and Poisson's ratio for GFRP plates

\begin{tabular}{|c|c|c|c|c|c|c|}
\hline \multirow{3}{*}{ Group } & \multicolumn{3}{|c|}{ Transversal modulus of elasticity } & \multicolumn{3}{|c|}{ Poisson's ratio } \\
\hline & Value & Avg. & CoV. & \multirow{2}{*}{ Value } & \multirow{2}{*}{ Avg. } & CoV. \\
\hline & [GPa] & [GPa] & {$[\%]$} & & & {$[\%]$} \\
\hline 01 & 4.591 & \multirow{2}{*}{4.753} & \multirow{2}{*}{3.41} & 0.357 & \multirow{2}{*}{0.35} & \multirow{2}{*}{0.76} \\
\hline 02 & 4.915 & & & 0.351 & & \\
\hline
\end{tabular}

The average experimental values for the properties evaluated in this composite characterization were $\varepsilon=2.32 \mathrm{~mm}$, $\sigma_{p t . u}=164.2 \mathrm{MPa}, V_{f}=39.0 \%, E_{p t . l}=13.35 \mathrm{GPa}$, and $E_{p t . t}=4.75 \mathrm{GPa}$. They were similar to the expected values obtained by previous works [17], [18], [20], [21] that employed similar materials and fabrication process, which presented average properties values of $\varepsilon=2.00 \mathrm{~mm}, \sigma_{p t . u}=199.5 \mathrm{MPa}, V_{f}=40.8 \%, E_{p t . l}=12.65 \mathrm{GPa}$, e $E_{p t . t}=5.41 \mathrm{GPa}$. 


\subsection{Evaluation of production quality of the GFRP composites plates}

\subsubsection{Superficial extension of the plates}

The statistics used in this evaluation (i.e., the coefficient of variation) is an indicative of the precision of the production. Following to Pimentel-Gomes [26], a classification for the coefficients of variation, based on their magnitude, was adopted: Low, when inferior to 10\%; Average, when between $10 \%$ and $20 \%$; High, when between $20 \%$ and 30\%; and Very High, when higher than 30\%. The classes Low and Average are considered to indicate a satisfactory production quality condition.

By analysing the Table 2, it can be observed that, considering the ultimate tensile stress coefficients of variation, 18 samples can be classified as Low and 9 as Average. For the volume fraction of fibres, all samples can be classified as Low. This allowed to conclude that, considering the parameters evaluated, the plates presented satisfactory homogenous characteristics along their extension (i.e., the infusion process did not cause significant variations that could have compromised the homogeneity of the plates). This homogeneity was more evident in the volume fraction of fibres than in the ultimate tensile stress.

\subsubsection{Reproducibility of the infusion process employing materials of same origin}

The Figures 10 and 11 show the average values, and the respective dispersions, of the results obtained in the ultimate tensile stress and volume fraction of fibre. Each column represents a single plate result. For the ultimate tensile stress (Figure 10), a higher dispersion was observed in the Group 01 (Figure 10b) when compared to the other groups (Figure $10 \mathrm{c}$ and Figure 10d). For the volume fraction of fibre (Figure 11), a higher dispersion was observed in the Groups 01 and 02 (Figure 11b and Figure 11c) when compared to the Group 03 (Figure 11d).

The Table 5 presents the group's coefficients of variation that were calculated from the average results obtained in each GFRP composite plate in the ultimate tensile stress and volume fraction of fibre tests. It was observed that all results presented coefficients of variation classified as Low, according to the aforementioned criteria by PimentelGomes [26], with the exception of the ultimate tensile stress obtained in the Group 01, that presented an Average coefficient of variation. These results confirm the trend observed in the Figures 10 and 11, which consists in a higher dispersion in the ultimate tensile stress for the Group 01, and a lower dispersion for the volume fraction of fibre for the Group 03.

Aiming the validation of such trends, an Analysis of Variance (ANOVA) was performed with the data for each of the three groups, with results presented in the Table 6 . A p-value of 0.05 was adopted, which implied a confidence interval of $95 \%$.

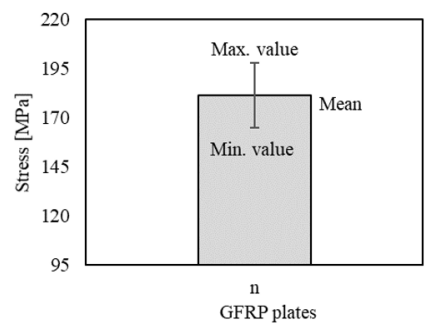

(a)

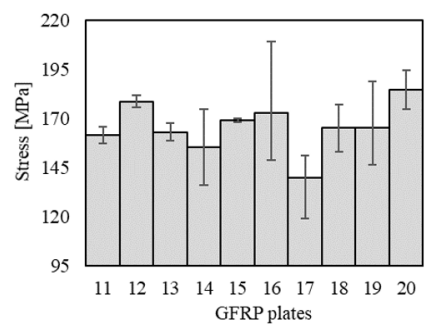

(c)

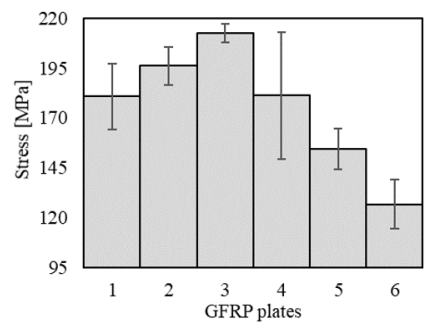

(b)

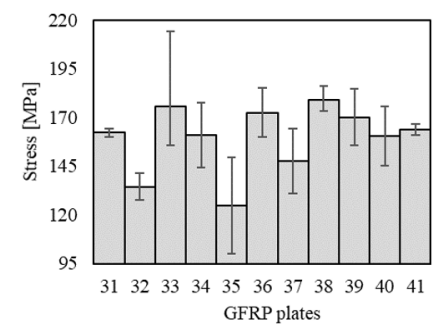

(d)

Figure 10. Ultimate tensile stress: (a) description of the constituent parts of the graphics; (b) Group 01; (c) Group 02; (d) Group 03. 


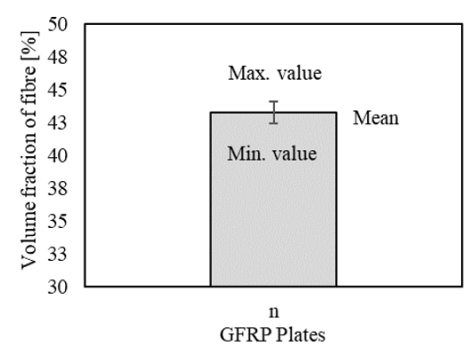

(a)

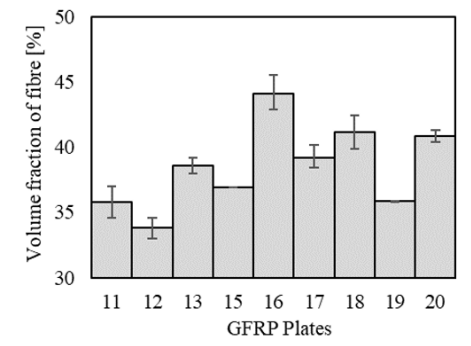

(c)

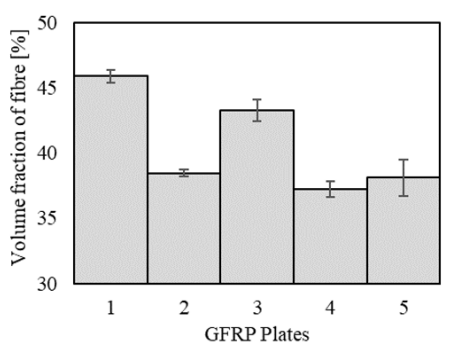

(b)

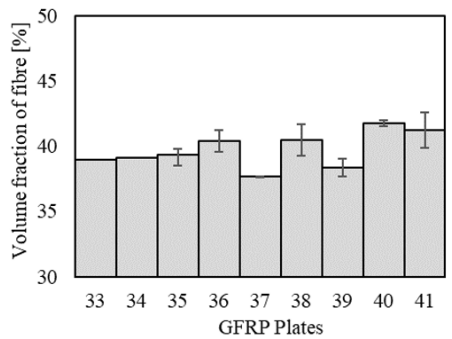

(d)

Figure 11. Volume fraction of fibre: (a) description of the constituent parts of the graphics; (b) Group 01; (c) Group 02; (d) Group 03.

Table 5. Coefficient of variation for Groups 01, 02 and 03: ultimate tensile stress and volume fraction of fibre.

\begin{tabular}{cccc}
\hline \multirow{2}{*}{ Group } & Ultimate tensile stress & Volume fraction of fibre \\
\cline { 2 - 4 } & {$[\%]$} & {$[\%]$} & 8.16 \\
\hline 01 & 15.96 & 7.75 \\
\hline 02 & 7.14 & 4.10 \\
\hline
\end{tabular}

Both the coefficients of variation and ANOVA suggest a satisfactory homogeneity in the results obtained for the ultimate tensile stress in all groups. This allows to infer that differences in the production process, due to minor variations in sequential infusion process, did not compromise the precision/repeatability of the production process, as far as the ultimate tensile stress is concerned.

Table 6. ANOVA results for Groups 01, 02 e 03

\begin{tabular}{|c|c|c|c|c|c|}
\hline \multirow{3}{*}{ Group } & \multirow{3}{*}{ Analysis } & \multicolumn{2}{|c|}{ Ultimate tensile stress } & \multicolumn{2}{|c|}{ Volume fraction of fibre } \\
\hline & & \multirow{2}{*}{ Value } & \multirow{2}{*}{$\begin{array}{c}\text { Significant } \\
\text { comparisons }\end{array}$} & \multirow{2}{*}{ Value } & Significant \\
\hline & & & & & comparisons \\
\hline \multirow{4}{*}{01} & $\mathrm{DF}$ & 5 & \multirow{4}{*}{ no } & 4 & \multirow{4}{*}{ yes } \\
\hline & MS & 1876.77 & & 28.9043 & \\
\hline & $F$ ratio & 3.418 & & 22.40 & \\
\hline & $p$ normal & 0.0833 & & 0.002163 & \\
\hline \multirow{4}{*}{02} & DF & 9 & \multirow{4}{*}{ no } & 8 & \multirow{4}{*}{ yes } \\
\hline & MS & 388.21 & & 24.4804 & \\
\hline & $F$ ratio & 1.020 & & 19.53 & \\
\hline & $p$ normal & 0.4724 & & 0.000018 & \\
\hline \multirow{4}{*}{03} & $\mathrm{DF}$ & 10 & \multirow{4}{*}{ no } & 8 & \multirow{4}{*}{ no } \\
\hline & MS & 646.72 & & 3.73156 & \\
\hline & $F$ ratio & 1.401 & & 3.012 & \\
\hline & $p$ normal & 0.2797 & & 0.052920 & \\
\hline
\end{tabular}


The volume fraction of fibre, however, presented results with statistically significant differences between the plates from Group 01 and 02, suggesting that the variations occurred between the production process of this groups resulted in different fibre content in these groups. In the Group 03, these statistically significant differences were not observed. These results suggest that there was a progressive improvement in the fabrication process, since Groups 01 and 02 were produced before Group 03. Nonetheless, even though the differences observed in the Groups 01 and 02 can be considered an indicative of some error in the production quality of the composites, such error did not appear in the ultimate tensile stress property, which, as mentioned before, is the main characteristic of interest. The overall homogeneity of the plate composites of the same production group was, therefore, considered satisfactory. Moreover, the fact that all coefficients of variation obtained in the test results for the volume fraction of fibres were considered Low also supports this conclusion.

\subsubsection{Reproducibility of the infusion process employing materials of different origins}

The variability of properties between composite plates of different production groups was analysed to assess the reproducibility of the composites' properties when produced with materials from different origins/manufacturer's batch. The Figures 12 and 13 present the histograms generated from the frequency distribution of results obtained in the ultimate tensile stress and volume fraction of fibres, respectively. Normal distribution curves were fitted to each histogram.

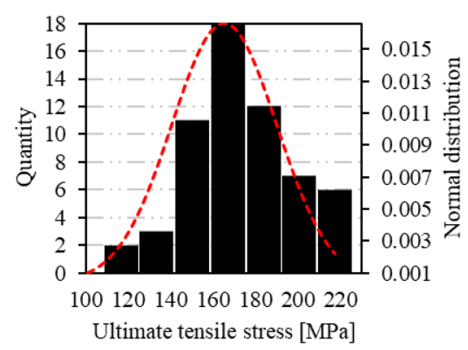

(a)

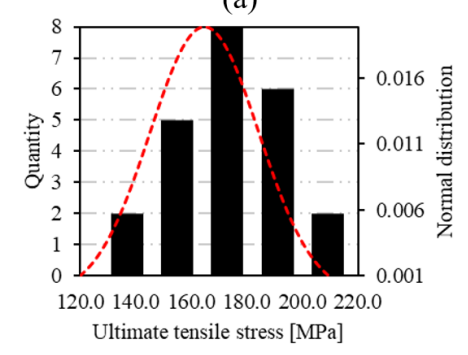

(c)

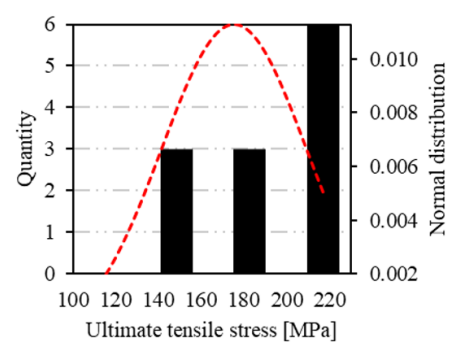

(b)

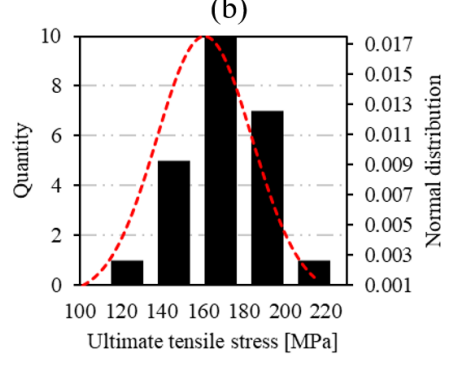

(d)

Figure 12. Histograms and normal distribution curves of ultimate tensile stress test results for: (a) all specimens; (b) group A; (c) group B; (d) group C.

Even though the Figures $12 \mathrm{~b}$ and $13 \mathrm{~b}$, both corresponding to the Group 01 , and the Figure $12 \mathrm{~d}$, which corresponds to the Group 03, do not visually seem to present a good adherence between the fitted curve and the histogram, this adherence was verified for all histograms with a confidence level of $95 \%$, i.e. with p-values higher than 0.05 , by using the Shapiro-Wilk test.

The Figure 14 presents the box diagrams for the test results of ultimate tensile stress (Figure 14b), volume fraction of fibres (Figure 14c) and longitudinal tensile modulus of elasticity (Figure 14d), for the Groups 01, 02 and 03 . The visual analysis of the diagrams suggests a satisfactory dispersion for all results.

To statistically support the analysis of the box diagrams, an ANOVA test was conducted on the data. The results are presented on Table 7. A p-value of 0.05 was adopted, implying a confidence level of $95 \%$. The p-values obtained suggest that the data did not present statistically significant differences. This indicates that the variation on material's origin/manufacture's batch did not cause significant differences in the characteristics of the composite plates produced. 


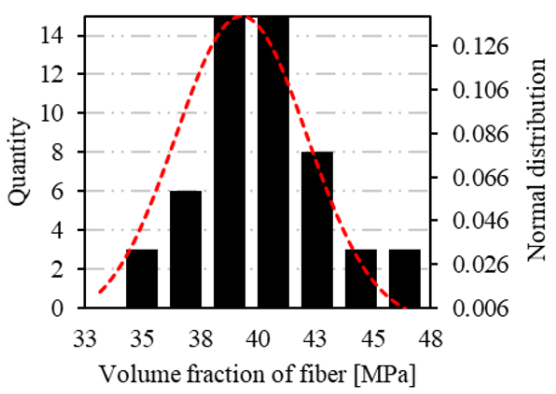

(a)

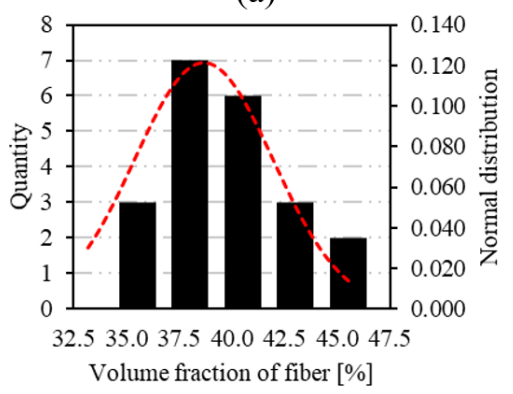

(c)

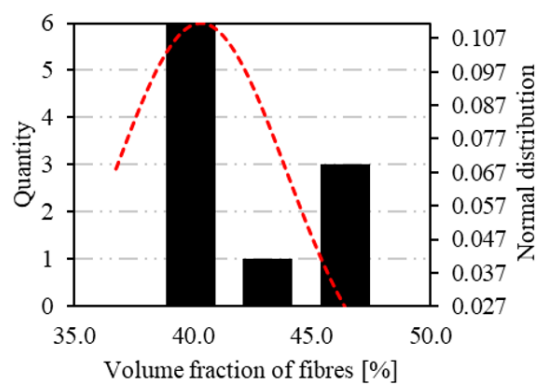

(b)

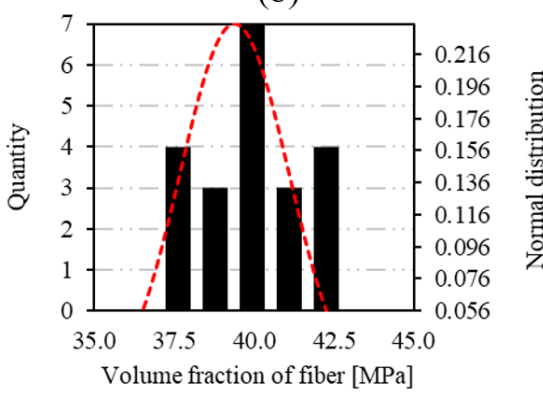

(d)

Figure 13. Histograms and normal distribution curves of volume fraction of fibre test results for: (a) all specimens; (b) group A; (c) group B; (d) group C.

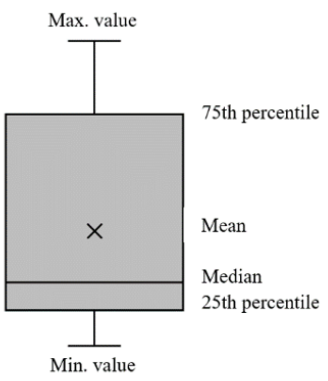

(a)

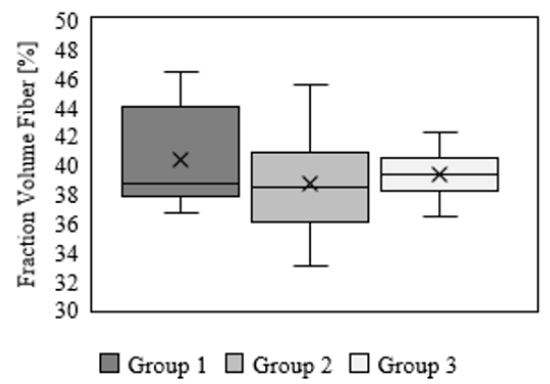

(c)

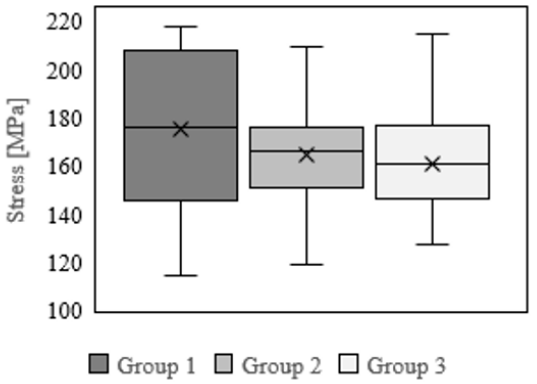

(b)

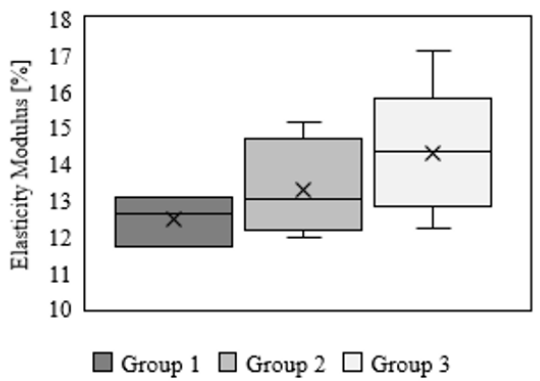

(d)

Figure 14. Box diagrams: (a) graphics legend; (b) ultimate tensile stress; (c) volume fraction of fibres; (d) longitudinal modulus of elasticity.

\subsection{Push-out tests}

The Figure 15 presents the failure modes of the tested connectors. In all the figures, the right-hand side represents the portion of the connector embedded in the internal concrete layer, while the left-hand side represents the portion 
embedded in the external concrete layer. The rupture planes did not present a very well clear trend, although a general tendency of $45^{\circ}$ inclined planes, starting from the superior external surface to the inferior internal surface, can be identified. Other works have presented clearer failure modes [2] due to the utilization of fibre oriented composites.

Table 7. ANOVA for evaluation of statistically significant differences in the characteristics of the composite plates from different production groups.

\begin{tabular}{|c|c|c|c|c|c|c|c|}
\hline \multirow{3}{*}{ Group } & \multirow{3}{*}{ Analysis } & \multicolumn{2}{|c|}{ Ultimate tensile stress } & \multicolumn{2}{|c|}{ Volume fraction of fibre } & \multicolumn{2}{|c|}{$\begin{array}{c}\text { Longitudinal tensile modulus } \\
\text { of elasticity }\end{array}$} \\
\hline & & \multirow{2}{*}{ Value } & \multirow{2}{*}{$\begin{array}{c}\text { Significant } \\
\text { comparisons }\end{array}$} & \multirow{2}{*}{ Value } & \multirow{2}{*}{$\begin{array}{c}\text { Significant } \\
\text { comparisons }\end{array}$} & \multirow{2}{*}{ Value } & Significant \\
\hline & & & & & & & comparisons \\
\hline \multirow{4}{*}{ All } & $\mathrm{DF}$ & 2 & \multirow{4}{*}{ no } & 2 & \multirow{4}{*}{ no } & 2 & \multirow{4}{*}{ no } \\
\hline & MS & 851.285 & & 10.234 & & 3.325 & \\
\hline & $F$ ratio & 1.419 & & 1.270 & & 1.537 & \\
\hline & $p$ normal & 0.25004 & & 0.28998 & & 0.26650 & \\
\hline
\end{tabular}

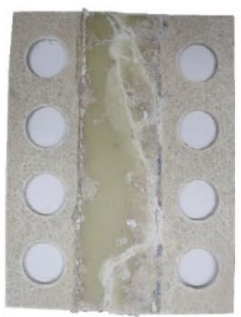

(a)

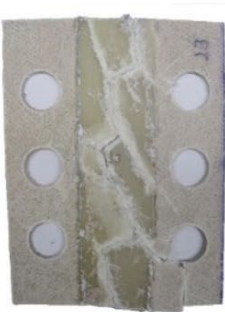

(b)

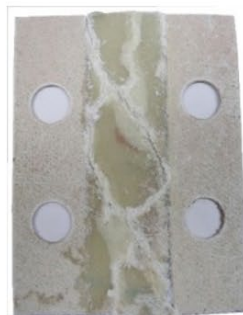

(c)

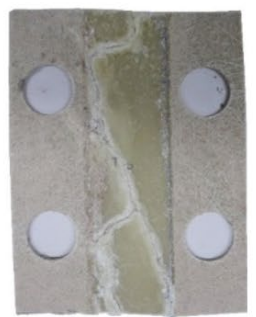

(d)

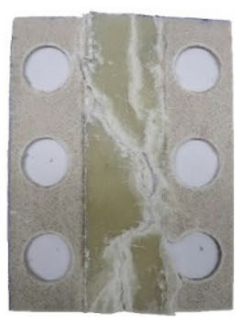

(e)

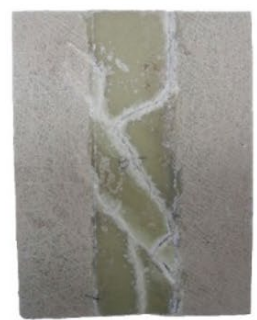

(f)

Figure 15. Failure modes of the tested connectors: (a) SP-25.4-1.75; (b) 25.4-2.00; (c) SP-25.4-3.00; (d) SP-31.75-2.00; (e) SP31.75-3.00; (f) SP-CTL.

The Figure 16 presents the load-relative displacement curve for each of the tested specimens. Three curves were plotted in each graphic of Figure 16, corresponding to the three replicates of the same connector. The load refers to the load acquired during the test divided by two, to account for the double-shear of the two connectors inside the tested specimen, assuming an equivalent distribution of internal forces.

During the test execution, it was not observed visible concrete cracks close to the connector's region. The connector's behaviour was, in general, very stiff until failure. After failure, a very erratic behaviour was observed, with some connectors presenting a well-defined yielding plateau, while others presented a sudden load reduction.

The Table 8 summarizes the push-out test results, presenting, for each group of replicates: the average maximum peak load; the average relative displacement associated to the maximum peak load of each replicate $\left(Q_{l o . u}\right)$; and the average connector's stiffness $\left(K_{f}\right)$, calculated, for each specimen, as the ratio between the maximum peak load and the associated relative displacement $\left(S_{l o . u}\right)$. The $K_{f}$ parameter was calculated similar to previous works [2], assuming the simplification of a linear behaviour up to the peak loading, which, in fact, does not occur. This simplified analysis was performed due to the high variation observed in the $S_{l o . u}$ results and provided a measurement of the general trend of the results. Currently, there are no standard recommendations for the stiffness evaluation of sandwich panels connectors.

Bar chart, presenting the average, minimum and maximum values of each parameter evaluated in the push-out test, are presented in the Figure 17. The observed magnitude of the error bars suggests, in general, a high variability in all specimens' results. This is supported by the average coefficients of variation, presented on Table 8 , with values of $7.66 \%, 35.58 \%$ and $35.44 \%$ for the maximum loading, relative displacement and stiffness, respectively. 


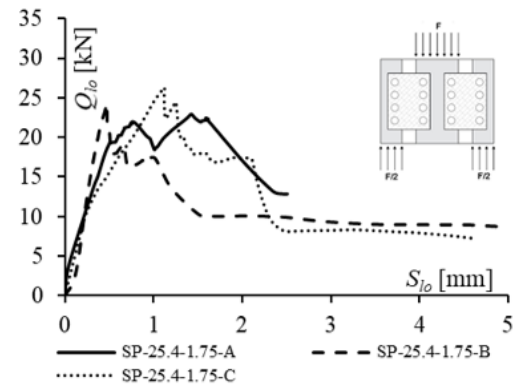

(a)

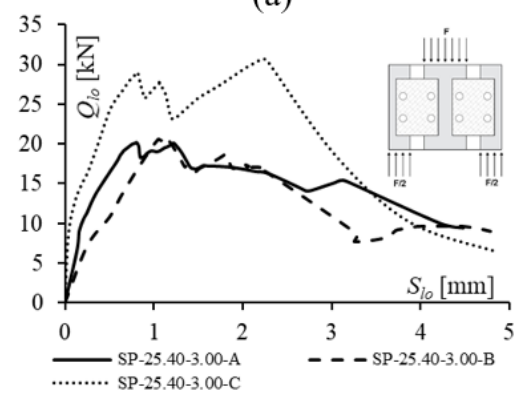

(c)

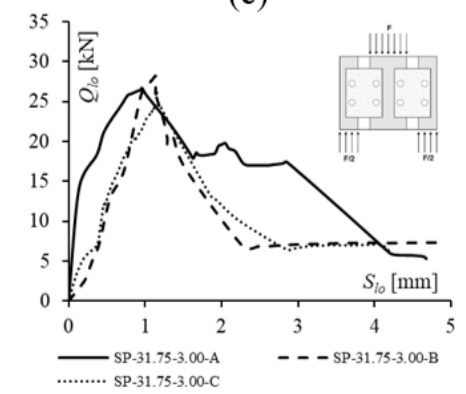

(e)

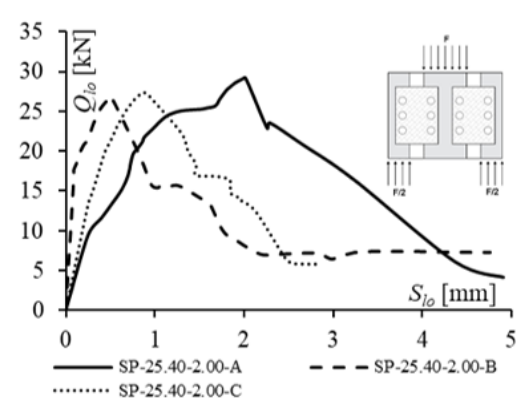

(b)

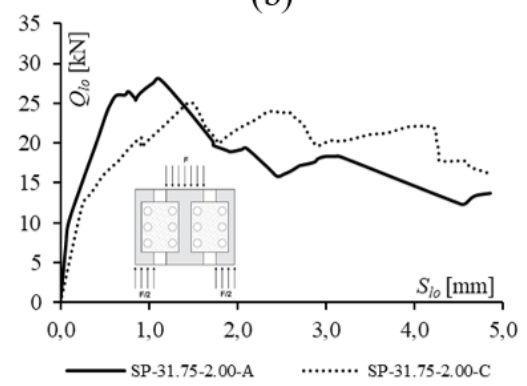

(d)

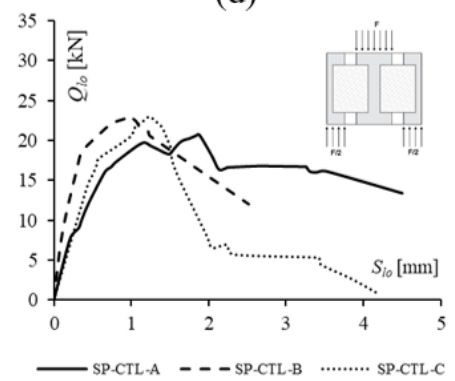

(f)

Figure 16. Load-relative displacement curves for: (a) SP-25.40-1.75; (b) SP-25.40-2.00; (c) SP-25.40-3.00; (d) SP-25.40-3.00 C; (e) SP-31.75-3.00; (f) SP-25.40-2.00.

Table 8. Push-out test results.

\begin{tabular}{|c|c|c|c|c|c|c|c|}
\hline \multirow{3}{*}{ Specimen } & \multirow{3}{*}{ Sample size } & \multicolumn{2}{|c|}{ Ultimate load } & \multicolumn{2}{|c|}{ Relative slip } & \multicolumn{2}{|c|}{ Stiffness } \\
\hline & & Avg. & CoV. & Avg. & CoV. & Avg. & CoV. \\
\hline & & {$[\mathrm{kN}]$} & {$[\%]$} & {$[\mathrm{mm}]$} & {$[\%]$} & {$[\mathrm{kN} / \mathbf{m m}]$} & {$[\%]$} \\
\hline SP-25.40-1.75 (1) & 3 & 24.50 & 5.77 & 1.01 & 39.43 & 30.15 & 49.79 \\
\hline SP-25.40-2.00 (2) & 3 & 27.85 & 3.56 & 1.13 & 56.80 & 33.02 & 47.92 \\
\hline SP-25.40-3.00 (3) & 3 & 23.94 & 20.14 & 1.39 & 44.19 & 19.09 & 23.93 \\
\hline SP-31.75-2.00 (4) & 3 & 25.89 & 6.20 & 1.29 & 13.40 & 21.20 & 18.89 \\
\hline SP-31.75-3.00 (5) & 3 & 26.51 & 5.54 & $0.94 *$ & 32.25 & $32.71 *$ & 42.44 \\
\hline SP-CTL (6) & 3 & 22.21 & 4.77 & 1.37 & 27.44 & 17.57 & 29.66 \\
\hline Average & & & 7.66 & & 35.58 & & 35.44 \\
\hline
\end{tabular}

*: The relative displacement and stiffness of the SP-31.75-3.00 specimen were computed with just two samples.

Despite the elevated coefficients of variation, some trends can be observed. In the case of maximum load, it was observed that all groups presented values higher than the control specimen. Furthermore, only the SP-25.40-3.00 specimen presented a relative displacement equivalent to that of the control specimen, while all the others presented lower displacements. For the stiffness, only the SP-25.40-3.00 presented values close to the control specimen, with all 
the others presenting higher values. Therefore, it was inferred that the perforated connectors tend to present higher ultimate load values, lower relative displacements and higher stiffness.

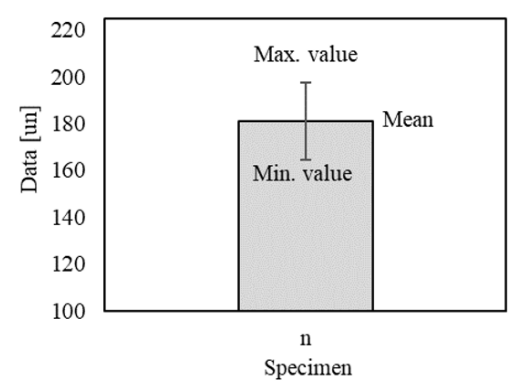

(a)

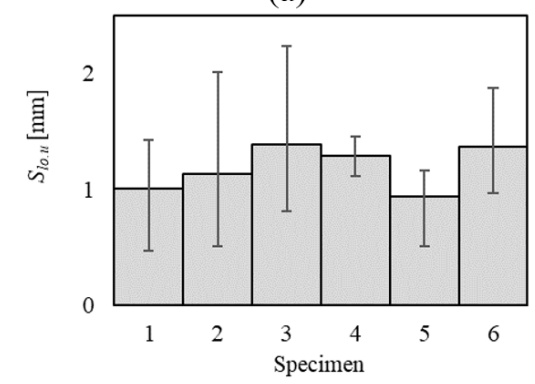

(c)

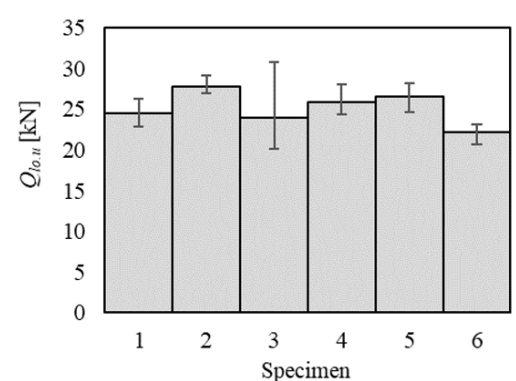

(b)

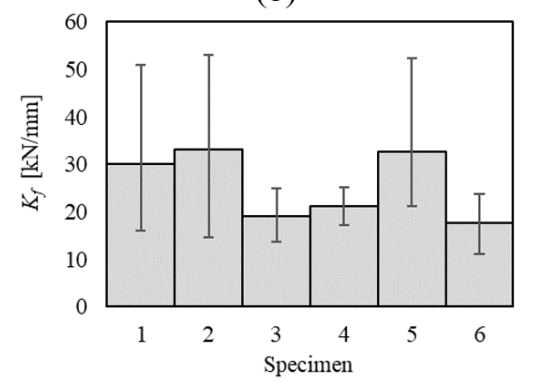

(d)

Figure 17. Bar chart of push-out test results: (a) graphics legend; (b) ultimate load; (c) relative displacement; (d) stiffness.

It is also interesting to compare these results to steel pin connectors results found on the literature, to evaluate the performance of the produced PERFOFRP connectors in comparison to a currently widely used connector. In a comprehensive study, it was found that a bending angle of $45^{\circ}$ resulted in the best performance for $5.8 \mathrm{~mm}$ diameter steel pin connectors [16]. For this specific connector, it was found that the average ultimate load and stiffness were, respectively: $22.3 \mathrm{kN}$ and $15.0 \mathrm{kN} / \mathrm{mm}$, under tensile load until yielding; $18.1 \mathrm{kN}$ and $16.5 \mathrm{kN} / \mathrm{mm}$, under compressive load until buckling [16]. Comparing these results to the specimen SP-25.40-2.00, which was the specimen with the best performance in the present study, it can be observed a gain in ultimate load of $24.7 \%$ and $54.3 \%$, considering the tensile and compressive behaviour, respectively. Furthermore, the SP-25.40-2.00 presented a stiffness $219.8 \%$ and $199.6 \%$ higher than those obtained for the steel pin connector under tension and compression, respectively.

The Figure 18a presents the ultimate load of the connectors in terms of the total area of holes. The number indicated at the side of each symbol corresponds to the hole spacing. One of the objectives of the push-out tests was to determine the hole spacing that leads to the maximum ultimate load, considering each hole diameter studied. This optimization could be performed by finding the maxima of a function correlating the ultimate load to the hole spacing, for each hole diameter, or, alternatively, to another parameter that is dependent on the hole spacing, such as the total area of holes, which is dependent on hole spacing accordingly to the rules explained in the item 2.2.1. The simplest function to be fitted to the experimental data, to allow such optimization, would be a parabola. From this, a visual inspection of the Figure 18a suggested that, for connectors with $25.40 \mathrm{~mm}$ holes, the optimization most likely occurs for spacings around 2.00 times the hole diameter, while for connectors with $31.75 \mathrm{~mm}$ holes, the optimization apparently occurs for spacings between 3.00 and 2.00 .

The Figure $18 \mathrm{~b}$ presents the ultimate load values $\left(Q_{l o . u}\right)$ of each specimen type, sorted in ascending order, as well as the ultimate load gain, in percentage, in relation to the control specimen's ultimate load. It also presents the total area of holes $\left(A_{f}\right)$, in the secondary vertical axis. The gains ranged from $8 \%$ to $25 \%$ in relation to the control group, and the highest ultimate load was that of specimen SP-25.40-2.00, encoded by the group code 2 in the graph, even though its total area of holes is not the smallest. This illustrates that the ultimate load is also sensitive to the hole configuration, with both parameters analysed (diameter and spacing) inducing visible influences in the connector's performance. 


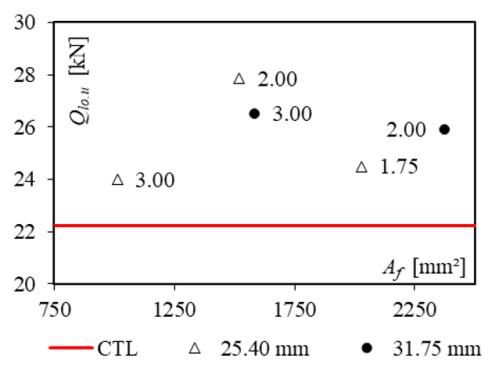

(a)

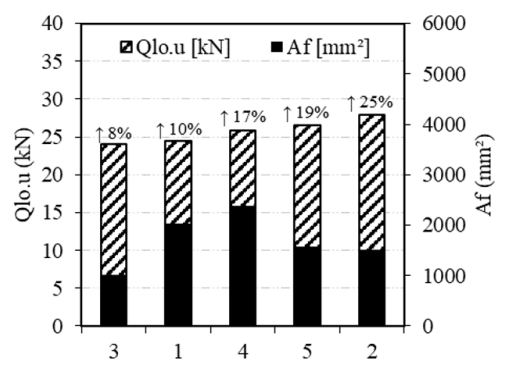

(b)

Figure 18. Relation between (a) the ultimate load by the total area of holes, for each hole diameter; (b) ultimate load increase for each specimen type, and the total area of holes, in relation to the control group.

\section{CONCLUSIONS}

This work presented the evaluation of production quality and the mechanical behaviour of shear connectors manufactured with perforated GFRP plates for insulated pre-cast concrete wall panels (sandwich panels), produced with an in-house developed low-cost vacuum assisted resin infusion system. A complete explanation of the low-cost production system and process was also presented. Moreover, the mechanical behaviour of the shear connectors was assessed by 18 specimens, produced as representative models of the shear connector in insulated pre-cast concrete wall panels, subjected to double-shear push-out tests. The main conclusions were:

a) The in-house developed low-cost vacuum assisted resin infusion process used to produce the GFRP composite plates is an original contribution of this work, with a high potential use in industry and research, since the low-cost (the required investment for the acquisition of raw materials was around 1/10 of the cost of commercially available connectors) and easy-access materials required to build it can be acquired and used at, virtually, any place and ambient.

b) The average properties of the GFRP composite plates produced with the low-cost production systems were: $2.32 \mathrm{~mm}$ thickness; 164.24 MPa ultimate tensile stress; 39.04\% volume fraction of fibre; $13.35 \mathrm{GPa}$ longitudinal modulus of elasticity; $4.753 \mathrm{GPa}$ transversal elastic modulus; and 0.35 Poisson's ratio. These values were remarkably close to those obtained in previous research that employed similar materials and production process.

c) The production quality of the plates, assessed by statistical analysis of the ultimate tensile stress and volume fraction of fibre of samples taken from the plates, was considered satisfactory, validating the production process employed in this work. This analysis was performed in different levels: samples from the same plate; samples from plates from the same production group (i.e., plates produced with materials from the same origin); samples from plates with different origin.

d) The push-out tests demonstrated that the perforated connectors presented, when compared to non-perforated connectors, a strength gain ranging from $8 \%$ to $25 \%$ (depending on the hole diameter and spacing used), lower relative displacements, and higher stiffness levels. It was also observed that a hole spacing of 2.00 times the hole diameter induced the best performance (i.e., the highest ultimate load value), for the hole diameter of $25.40 \mathrm{~mm}$, while this optimum point, for the hole diameter of $31.75 \mathrm{~mm}$, is probably reached with a hole spacing between 2.00 and 3.00 .

\section{ACKNOWLEDGEMENTS}

The authors would like to thank the financial support provided by Brazilian Coordination of Superior Level Staff Improvement (CAPES) and Brazilian National Council for Scientific and Technological Development (CNPq).

\section{CITATIONS}

[1] PCI Committee on Precast Sandwich Wall Panels, "PCI Committee Report: state of the art of precast/prestressed concrete sandwich wall panels," PCIJ., vol. 56, no. 2, pp. 131-176, 2011.

[2] J. Q. Huang and J. G. Dai, "Direct shear tests of glass fiber reinforced polymer connectors for use in precast concrete sandwich panels," Compos. Struct., vol. 207, pp. 136-147, 2019.

[3] C. Naito, J. Hoemann, M. Beacraft, and B. Bewick, "Performance and characterization of shear ties for use in insulated precast concrete sandwich wall panels," J. Struct. Eng., vol. 138, no. 1, pp. 52-61, 2012. 
[4] A. Benayoune, A. A. A. Samad, D. N. Trikha, A. A. A. Ali, and S. H. M. Ellinna, "Flexural behaviour of pre-cast concrete sandwich composite panel: experimental and theoretical investigations," Constr. Build. Mater., vol. 22, no. 4, pp. 580-592, 2008.

[5] T. D. Bush and G. L. Stine, "Flexural behavior of composite precast concrete sandwich panels with continuous truss connectors," $P C I$ J., vol. 39, no. 2, pp. 112-121, 1994.

[6] T. D. Bush and Z. Wu, "Flexural analysis of prestressed concrete sandwich panels with truss connectors," PCI J., vol. 43, no. 5, pp. 76-86, 1998.

[7] W. C. MacCall, "Thermal properties of sandwich panels," Concr. Int. Des. Constr., vol. 7, pp. 34-41, 1985.

[8] D. Salmon, A. Einea, M. K. Tadros, and T. D. Culp, "Ful scale testing of precast concrete sandwich panels," ACI Struct. J., vol. 94, no. 4, pp. 354-362, 1997.

[9] J. H. Kim and Y. C. You, "Composite behavior of a novel insulated concrete sandwich wall panel reinforced with GFRP shear grids: effects of insulation types," Materials, vol. 8, no. 3, pp. 899-913, 2015.

[10] T. K. Hassan and S. H. Rizkalla, "Analysis and design guidelines of precast, prestressed concrete, composite load-bearing sandwich wall panels reinforced with CFRP grid," PCI J., vol. 55, no. 2, pp. 147-162, 2010.

[11] B. A. Frankl, G. W. Lucier, T. K. Hassan, and S. H. Rizkalla, "Behavior of precast, prestressed concrete sandwich wall panels reinforced with CFRP shear grid," PCI J., vol. 56, no. 2, pp. 42-54, 2011.

[12] H. Gleich, "New carbon fiber reinforcement advances sandwich wall panels," Prod. Watch, pp. 61-63, 2007.

[13] K.-B. Choi, W.-C. Choi, L. Feo, S.-J. Jang, and H.-D. Yun, "In-plane shear behavior of insulated precast concrete sandwich panels reinforced with corrugated GFRP shear connectors," Compos., Part B Eng., vol. 79, pp. 419-429, 2015.

[14] C. P. Pantelides, R. Surapaneni, and L. D. Reaveley, "Structural performance of hybrid GFRP/steel concrete sandwich panels," J. Compos. Constr., vol. 12, no. 5, pp. 570-576, 2008.

[15] K. Hodicky, G. Sopal, S. Rizkalla, T. Hulin, and H. Stang, "Analytical model for CFRP-strengthened prestressed concrete girders subject to cyclic loading," J. Compos. Constr., vol. 19, no. 5, 2015.

[16] D. G. Tomlinson, N. Teixeira, and A. Fam, "New shear connector design for insulated concrete sandwich panels using basalt fiberreinforced polymer bars," J. Compos. Constr., vol. 20, no. 4, pp. 1-13, 2016.

[17] R. Lameiras, J. Barros, M. Azenha, and I. B. Valente, "Development of sandwich panels combining fibre reinforced concrete layers and fibre reinforced polymer connectors. Part II: evaluation of mechanical behaviour," Compos. Struct., vol. 105, pp. 460-470, 2013.

[18] R. Lameiras, J. Barros, I. B. Valente, and M. Azenha, "Development of sandwich panels combining fibre reinforced concrete layers and fibre reinforced polymer connectors. Part I: conception and pull-out tests," Compos. Struct., vol. 105, pp. 446-459, 2013.

[19] H. D. Young and R. A. Freedman, Física I, 12th ed. São Paulo: Addison Wesley, 2008.

[20] R. Lameiras, J. A. O. Barros, I. B. Valente, J. Xavier, and M. Azenha, "Pull-out behaviour of glass-fibre reinforced polymer perforated plate connectors embedded in concrete. Part II: prediction of load carrying capacity," Constr. Build. Mater., vol. 169, pp. 142-164, Apr 2018.

[21] R. Lameiras, I. B. Valente, J. A. O. Barros, M. Azenha, and C. Gonçalves, "Pull-out behaviour of Glass-Fibre Reinforced Polymer perforated plate connectors embedded in concrete. Part I: experimental program," Constr. Build. Mater., vol. 162, pp. 155-169, Feb 2018.

[22] A. Chen, T. G. Norris, P. M. Hopkins, and M. Yossef, "Experimental investigation and finite element analysis of flexural behavior of insulated concrete sandwich panels with FRP plate shear connectors," Eng. Struct., vol. 98, pp. 95-108, 2015.

[23] T. G. Norris and A. Chen, "Development of insulated FRP-confined Precast Concrete Sandwich panel with side and top confining plates and dry bond," Compos. Struct., vol. 152, pp. 444-454, 2016.

[24] American Society for Testing and Materials, Standard Test Method for Tensile Properties of Polymer Matrix Composite Materials, ASTM D3039/D3039M, 2017, pp. 1-13.

[25] American Society for Testing and Materials, Standard Test Method for Ignition Loss of Cured Reinforced Resin, ASTM D2584, 2018.

[26] F. Pimentel-Gomes, Experimental Statistics Course, 15th ed. Piracicaba: FEALQ, 2009.

Author contributions: JKFS and RRR.: conceptualization, formal analysis, writing, methodology. RML: supervision, proofreading.

Editors: Vladimir Guilherme Haach, Guilherme Aris Parsekian. 